\title{
The Reinforcing Effect of Graphene on the Mechanical Properties of Carbon-Epoxy Composites
}

\author{
Hadimani Shivakumar',2, N. M. Renukappa ${ }^{2 *}$, K. N. Shivakumar ${ }^{3}$, B. Suresha ${ }^{4}$ \\ ${ }^{1}$ Department of Electronics and Communication Engineering, Kalpataru Institute of Technology (Visvesvaraya Technological \\ University, Belagavi) Tiptur, Karnataka, India \\ ${ }^{2}$ Department of Electronics and Communication Engineering, JSS Science and Technology University, Mysuru, Karnataka, India \\ ${ }^{3}$ Centers for Composite Materials Research, North Carolina A \& T State University, Greensboro, NC, USA \\ ${ }^{4}$ Center for Composite Materials Research, The National Institute of Engineering, Mysuru, India \\ Email: *renunijagal@gmail.com, *sureshab@nie.ac.in
}

How to cite this paper: Shivakumar, H., Renukappa, N.M., Shivakumar, K.N. and Suresha, B. (2020) The Reinforcing Effect of Graphene on the Mechanical Properties of Carbon-Epoxy Composites. Open Journal of Composite Materials, 10, 27-44. https://doi.org/10.4236/ojcm.2020.102003

Received: April 10, 2020

Accepted: April 27, 2020

Published: April 30, 2020

Copyright (๑) 2020 by author(s) and Scientific Research Publishing Inc. This work is licensed under the Creative Commons Attribution International License (CC BY 4.0).

http://creativecommons.org/licenses/by/4.0/

\begin{abstract}
Graphene nanoplatelets (GNPs) are novel nanofillers holding attractive characteristics, including vigorous compatibility with majority polymers, outstanding mechanical, thermal, and electrical properties. In this study, the outstanding GNPs filler was reinforced to the epoxy matrix and carbon fabric/epoxy hybrid composite slabs to enrich their mechanical properties. Graphene nanoplatelets of $0.5,1,1.5$ and 2 weight percentages were integrated into the epoxy and the physico-mechanical (microstructure, density, tensile, flexural and impact strength) properties were investigated. Furthermore, the mechanical properties of unfilled and $1 \mathrm{wt} \%$ GNPs filled carbon fabric/epoxy hybrid composite slabs were investigated. Subsequently, noteworthy improvement in the mechanical properties was conquered for the carbon fabric/epoxy hybrid composites.
\end{abstract}

\section{Keywords}

Graphene Nanoplatelets, Carbon Fabric/Epoxy Hybrid Composite, Physico-Mechanical Properties, Impact Strength

\section{Introduction}

Over the past few years, extensive research has been carried out in polymer based composites, especially the thermoset epoxy matrix material strengthened with synthetic fibers and nanofillers, chiefly owing to the noteworthy enrichment of mechanical, thermo-mechanical, and electrical properties at a very low 
loading ( $<3 \mathrm{wt} \%)$ of nanoparticles, compared to unfilled and micron-sized epoxy/fiber hybrid composites [1]-[6]. The pragmatic enhancements are frequently achieved by the hefty aspect ratio and large specific surface area of nano-dimensioned fillers composed with the paramount dispersed structure and better interface of nanoparticles with the polymer matrix material [7] [8] [9] [10].

Epoxy matrix material is one of the most commonly used primary phases in a composite because of lesser shrinkage, outstanding adhesion and better resistance to solvent [11] [12]. Some of the applications of epoxy based nanocomposites include aerospace, automotive, marine, sporting goods, construction, structures, electrical and electronic systems, biomedical devices, power plants, adhesives, paints and coatings, industrial tooling and other general consumer products [12]. There is a growing need for multi-phase composites with multifunctional properties such as augmented mechanical, thermal, electrical, and damp proof properties to satisfy the requests of voluminous aerospace, automotive, and electrical applications. Also, it is very well acknowledged that only mono-composite may not be able to encounter the prerequisite [13]. The mixture of fiber as primary strengthening phase and secondary phase as nanofiller combinations could be operational to get the multifunctional properties [10] [14] [15] [16].

In the recent years, accessibility to the nanofillers has unwrapped an innovative field to manufacture hybrid composites with multifunctional properties. A number of investigations proved enhancement in multifunctional properties of epoxy/carbon fiber composite with nanofillers for example graphite, graphene oxide, graphene platelets, carbon nanotubes, nanoclay, etc. [10] [16] [17] [18] [19] [20]. The research community already recognized that very little volume of nanofillers can significantly improve the electrical, mechanical, and thermo-mechanical, and damping properties of the carbon-epoxy hybrid composites.

Numerous specialists have conveyed the distinctive creation techniques to achieve the best mechanical presentation of epoxy/carbon fiber strengthened composite with different inorganic nanofillers [21] [22]. Graphene is single, slight layer graphite and most grounded material on the planet [23]. Mechanical properties of graphene are modulus $1 \mathrm{TPa}$, and strength of $130 \mathrm{GPa}$ [24]. Graphene nanoplatelets (GNPs) have created as one of the novel nanofillers for polymer nanocomposites with incredible harmony between multifunctional properties and cost. Various graphene scattering strategies into polymer frameworks have been investigated, to be specific mechanical blending, sonication and three-roll mill. King et al. [25] and Raza et al. [26] utilized mechanical blending strategy to scatter graphene into epoxy framework. They reported decrease of mechanical properties with increment of GNPs stacking. Researchers [27] [28] [29] [30] previously dispersed GNPs into a solvent and afterward the solution was blended in with epoxy and finally the solvent was removed by evaporation. It is notable that solvent removal is a challenge and any residual solvent will de- 
grade the mechanical properties of the matrix and responsible to bring poor composite material. The projected applications of graphene filled polymer based nanocomposites depend on the mechanical, thermal and electrical properties. Graphene filled polymer composites are currently starting to see and, thus, the potential applications of these new materials are still open for further research. Several graphene filled polymer nanocomposites for structural, electrical, and power plant applications are summarized in Table 1 [30]-[36].

Lately, reinforcing inorganic nanoparticles such as organo-modified montmorillonite, nano- $\mathrm{CaCO}_{3}$, and carbon nanotubes, graphene, has successfully improved the hardness and specific strength/stiffness of fiber strengthened polymer composites owing to the high intrinsic strength and large specific surface area of these nanofillers [16] [37] [38] [39] [40]. Among all these reinforcing materials, carbon nanotubes and graphene have the highest elastic modulus and the most suitable compatibility with the epoxy matrix because of their similar density to epoxy matrix [41] [42] [43]. Especially, graphene is much easier to disperse in the epoxy matrix than the entangled carbon nanotubes due to its huge transverse size [41] [42] and thus it shows prodigious budding reinforcing material for obtaining superior nanocomposites [41] [42] [44] [45] [46]. Larger surface area, excellent thermal conductivity, and very high Young's modulus have attracted widespread research interest in recent years with ever increasing scientific and technological stimulus.

Table 1. Applications of graphene modified epoxy mono/hybrid composites.

\begin{tabular}{|c|c|c|c|}
\hline Composites & Properties & Applications & Reference \\
\hline Graphene oxide-epoxy & $\begin{array}{l}\text { Storage modulus, tensile and flexural } \\
\text { properties, fracture toughness }\end{array}$ & Automotive and power plants & Wan et al. $[31]$ \\
\hline Epoxy/Graphene oxide & $\begin{array}{l}\text { Tensile properties, fracture toughness, } \\
\text { Dynamic mechanical properties, } \\
\text { Thermo-gravimetric analysis }\end{array}$ & Automotive and power plants & Wan et al. [32] \\
\hline Amine functionalized graphene filled epoxy & Tensile and electrical properties & Structural and Electrical & Ghaleb et al. [33] \\
\hline epoxy/Graphene oxide & Fracture toughness Electrical conductivity & Structural and Electrical & Wang et ai. [34] \\
\hline Epoxy/GNPs nanocomposites & $\begin{array}{l}\text { Thermomechanical properties and impact } \\
\text { strength }\end{array}$ & Structural & Seong and Kim [35] \\
\hline Graphene based GF/Ep & $\begin{array}{l}\text { Tensile and flexural properties } \\
\text { Fatigue life }\end{array}$ & Transport vehicles & Yavari et al. [36] \\
\hline Carbon fiber composites with GNPs & Mechanical and Electrical Properties & Structural and Electrical & Qin et al. [42] \\
\hline Carbon fiber/graphene oxide/epoxy & mechanical properties & Structural & Pathak et al. [19] \\
\hline Graphene modified carbon/epoxy & Electrical, thermal and mechanical & $\begin{array}{l}\text { Electrical, structural } \\
\text { and power plant }\end{array}$ & $\begin{array}{l}\text { Imran and } \\
\text { Shivakumar [22] }\end{array}$ \\
\hline GNPs/epoxy & Mechanical properties & Structural & King et al. [25] \\
\hline Pristine graphene/epoxy & Mechanical and electrical properties & Structural and Electrical & Wajid et al. [29] \\
\hline Graphene/epoxy composites & Mechanical properties & Structural & Tang et al. [30] \\
\hline Graphene oxide/woven carbon fiber/epoxy & Static and dynamic mechanical properties & Automotive and power plants & Adak et al. [10] \\
\hline
\end{tabular}


The purpose of this research work is to present a method to enhance the mechanical properties of carbon-epoxy composites with and without homogeneously dispersed GNPs for practical applications. Enhanced GNPs-epoxy interface bonding is achieved using three-roll mill. Homogeneous dispersion is further facilitated through sonication. Then the physico-mechanical properties measurements of mono-nanocomposites are presented. After detailed experimentation to achieve good mechanical properties, the carbon fabric reinforced epoxy (Cf-Ep) hybrid composites with $1 \mathrm{wt} \%$ GNPs was tested for hardness, tensile, flexure and impact properties. The current findings may signpost a noteworthy guidance for fabricating fiber reinforced thermoset composite reinforced with nanofillers having a mixture of good dispersion of filler in the matrix, improved interfacial bonding, superior hardness and high strength as well as modulus.

\section{Materials, Fabrication and Characterizations}

\subsection{Materials}

The material constituents are epoxy matrix (Epon 828) as primary phase, carbon fabric (3 K-AS4-8HS) as primary strengthening phase and graphene nanoplatelets (xGnP-25) as secondary strengthening phase. Epon 828 epoxy matrix was selected as primary continuous phase due to its wide applications in the field of polymer composite structures for automotive and aerospace applications. The dynamic viscosity of the Epon 828 was $11,000-15,000 \mathrm{cP}$ and epoxy equivalent weight was 185 - $192 \mathrm{~g} \cdot \mathrm{mol}^{-1}$. The curing agent selected was Epicure W, is an aromatic amine curing agent with amine hydrogen equivalent weight (AHEW) $43-46 \mathrm{~g} \cdot \mathrm{mol}^{-1}$. Its dynamic viscosity was $100-300 \mathrm{cP}$ and acts as curing agent at higher temperature. The mixing ratio Epon 828 to Epicure W was 100:26.4 by weight as per the supplier details. These materials were supplied by Miller-Stephenson Inc. Graphene nanoplatelets (xGnP M-25) was supplied by XG Sciences Inc. Graphene nanoplatelets dimensions are about 6 - $10 \mathrm{~nm}$ thick, surface area of $120-150 \mathrm{~m}^{2} \cdot \mathrm{g}^{-1}$ and average particle diameter is about $25 \mathrm{~nm}$. The woven carbon fabric was supplied by Northern Composites and has areal density of $372 \mathrm{~g} \cdot \mathrm{m}^{-2}$, and the density of the carbon fiber is $1.79 \mathrm{~g} \cdot \mathrm{cm}^{-3}$ [47].

\subsection{Fabrication of GNPs-Ep and Cf-Ep/GNPs Composites}

For the control material, epoxy matrix and curing agent were mixed by mechanical blending at $500 \mathrm{rpm}$ for $10 \mathrm{~min}$ and degassed at $60^{\circ} \mathrm{C}$ for $30 \mathrm{~min}$ to evacuate air bubbles. For the GNPs-Ep nanocomposites, GNPs (0.5 wt\%, 1 wt\%, $1.5 \mathrm{wt} \%$ and $2 \mathrm{wt} \%$ ) was distributed to epoxy matrix using three-roll mill. For this purpose, first epoxy and GNPs were blended by hand stirring for 2 min and using three-roll mill (Model EXAKT 80E). At that point the determined amount of curing agent was blended using mechanical mixer at $500 \mathrm{rpm}$ for $10 \mathrm{~min}$ and degassed at $60^{\circ} \mathrm{C}$ for $30 \mathrm{~min}$ to evacuate air bubbles like as control system. Details of matrix preparation were discussed in the previous study [22].

Dry woven carbon fabrics were impregnated by hand lay-up stacking. Around 
$20 \mathrm{~g}$ of resin was impregnated to each ply for both Cf-Ep and Cf-Ep/GNPs hybrid nanocomposites. At that point the resin impregnated fabrics were stowed and held it under vacuum $(0.1 \mathrm{MPa})$ for $12 \mathrm{~h}$. This vacuum pressure helps to evacuate trapped air incorporated during the lamination. Thickness of the laminates was constrained by adjusting the thickness of metallic plug. Compression molding was done by $(450 \mathrm{~mm} \times 450 \mathrm{~mm})$ Wabash Press (Model: 150-1818-2TM). Details of Cf-Ep and Cf-Ep/GNPs hybrid nanocomposites were discussed in the previous study [47].

\subsection{Characterizations of Composites}

The micro structural and physico-mechanical properties of GNPs-Ep and Cf-Ep/GNPs mono and hybrid composites respectively were evaluated by performing microstructure using scanning electron microscopy, density, porosity, hardness, and static mechanical properties measurements.

The densities of the coupons were determined using an electronic weighing machine (Mettler Toledo: Model AX 205) with a sensitivity of $0.0001 \mathrm{~g}$ conferring to the Archimedes principle and linked with the theoretical densities of Epon $828\left(\rho_{m}=1.16 \mathrm{~g} \cdot \mathrm{cm}^{-3}\right)$, GNPs $\left(\rho_{n p}=0.9 \mathrm{~g} \cdot \mathrm{cm}^{-3}\right)$ and carbon fiber $\left(\rho_{f}=1.79\right.$ $\left.\mathrm{g} \cdot \mathrm{cm}^{-3}\right)$. Theoretical densities of the fabricated composites coupons $\left(\rho_{c}\right)$, was calculated using equation:

$$
\frac{1}{\rho_{c}}=\frac{W_{m}}{\rho_{m}}+\frac{W_{f}}{\rho_{f}}+\frac{W_{n p}}{\rho_{n p}}
$$

where, $\rho_{c}$ is the density of the composites, $W_{m}, W_{f}, W_{n p}$ are the weight fractions of epoxy, carbon fiber and GNPs.

Micro structural studies help to show the accumulation and dispersion of nanoparticles over the prepared mono and hybrid composites. The fabricated composites were cut into $12 \mathrm{~mm} \times 12 \mathrm{~mm}$ square specimen and gold-sputtered before SEM examinations. A high resolution scanning electron microscope (FEI ESEM Quanta 200, Resolution $<5 \mathrm{~nm}, 25 \mathrm{kV} \mathrm{SE}$, Tungsten Emitter filament) was used.

Shore hardness meter (Shore-A to D) is one of the most generally utilized apparatus to measure hardness portrayal of polymeric materials. The hardness was assessed by the depth of notch caused by an inflexible ball under a spring force, the notch being transformed to hardness degrees on a circular scale extending from 0 to 100. The hardness scale from 0 to 100 is selected to such an extent that "0" expresses to a rubber having flexible modulus of zero and "100" speaks to elastic having interminable versatile modulus. Hardness tests were performed following ASTM D2240 standard. The hardness measurements were performed at ten different locations, and the mean value of hardness was calculated for each coupon. Hardness values reported in the present work is an average value of ten readings.

Mechanical test coupons were cut to standard size using a diamond tipped cutter. Tensile and flexural testing was conducted using a universal testing ma- 
chine (UTM: 100 kN, Kalpak software, Kalpak instruments and controls, Pune, India). At least five coupons for each composite prepared were tested to obtain mean data and all tests were carried out at room temperature. The tensile tests and flexural tests were carried out according to ASTM D638-15 and ASTM D790-03 respectively at a cross head speed of 2.5 and $1 \mathrm{~mm} / \mathrm{min}$.

Impact tests are designed to measure the resistance to failure to a suddenly applied load namely collision, falling object or instantaneous blow. Izod impact test measures the energy absorbed prior to failure. The Izod impact test was performed on a computerized Izod/Charpy impact tester (International Equipment's, Mumbai, India) $220 \mathrm{~V}, 60 \mathrm{~Hz}$ pendulum using 11 and $22 \mathrm{~J}$ hammers. Composite coupons were cut and machined from the composite slabs. The dimensions of $62.5 \mathrm{~mm} \times 12.7 \mathrm{~mm} \times 10 \mathrm{~mm}$ were specified by ASTM D256 standard [48]. At least five coupons for each composite prepared were tested to obtain mean data and all tests were carried out at room temperature.

\section{Results and Discussion}

\subsection{Microstructure of Mono and Hybrid Composites}

The fractured surface micrographs using SEM of a typical coupon from the mono and hybrid composites are displayed in Figures 1(a)-(d) and Figure 2(a), Figure 2 (b) in that order. It can be detected that the network of microcracks, ridges, dimpled forms, and clefts on the fracture surfaces are much more noticeable for the GNPs reinforced epoxy mono-composites (Figures 1(b)-(d)). It is also clear that GNPs debonded from other nanoparticles as well as from the epoxy matrix, and then microcracks diverted along epoxy matrix side (Figure 1(d)).
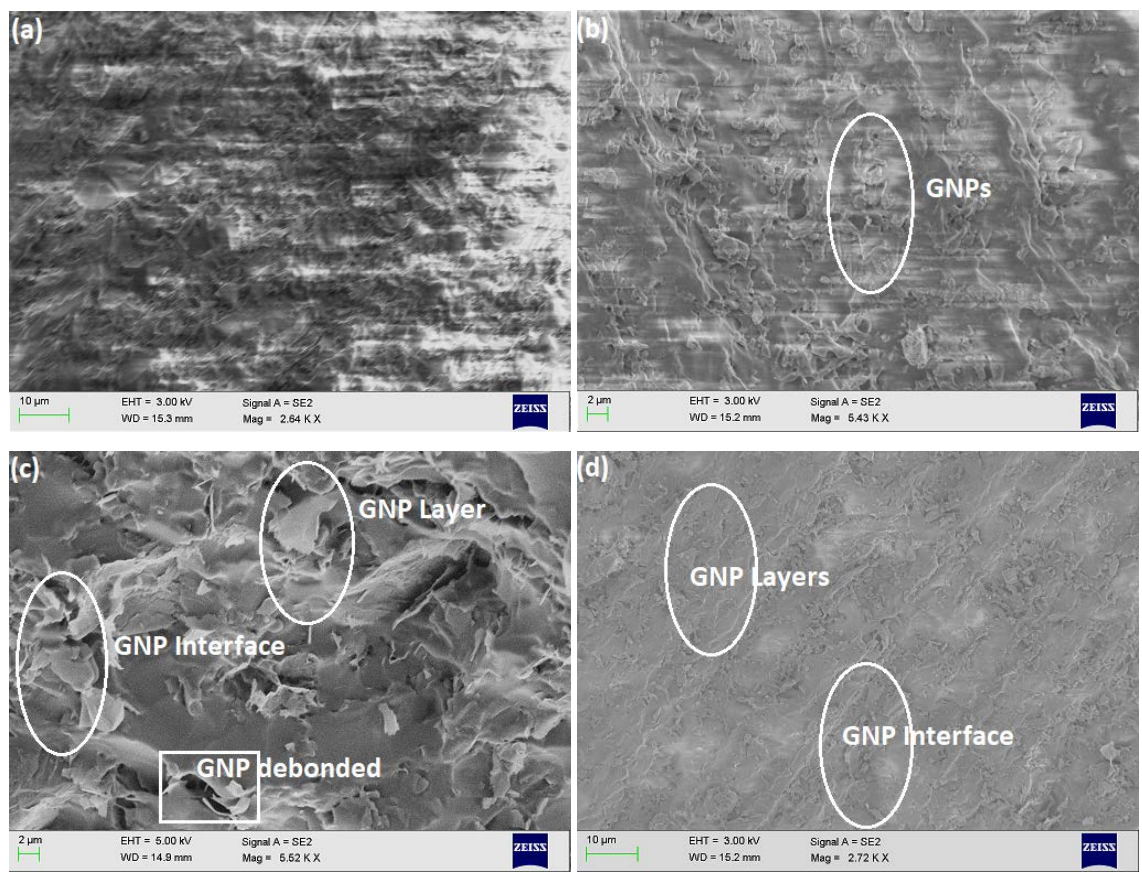

Figure 1. SEM micrographs of mono-composites: (a) Virgin epoxy, (b) 0.5 GNPs-Ep, (c) 1 GNPs-Ep, (d) 2GNPs-Ep. 

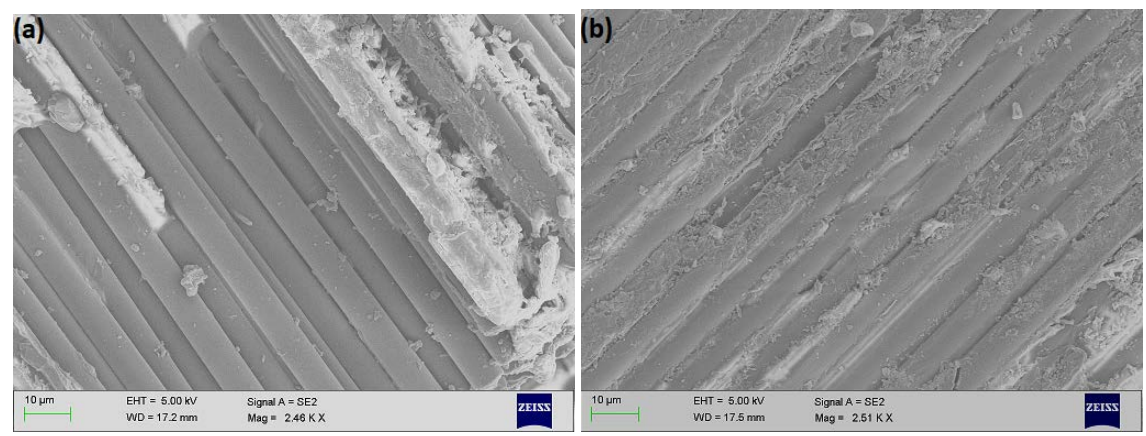

Figure 2. SEM micrographs of hybrid composites: (a) Cf-Ep/0.5GNPs, (b) Cf-Ep/1GNPs.

Even distribution of GNPs in the epoxy matrix is still puzzling and different methods of mixing of GNPs have been tried and three-roll mill mixing followed by sonication has been widely accepted as a potential method for even distribution of GNPs in the epoxy matrix material [47]. As expected, the GNPs were randomly -oriented and dispersed in the epoxy matrix (Figures 1(b)-(d)). The surface morphology for the virgin epoxy coupon, (Figure 1(a)) is much less featured than those of the GNPs reinforced epoxy mono-composite coupons. Also, the fractured surface displays a typical fracture pattern like fragile pattern and fracture surface is coarse and their crack becomes more unsystematic.

Figure 2 shows the fractured morphology of Cf-Ep and Cf-Ep/1GNPs composites. Interfacial failure demonstrates key contribution to the failure of the mono-Cf-Ep composite, which is obvious from its debonded fiber-matrix interfaces and charming fiber imprint as well as few fiber breakages as shown in Figure 2(a). Incorporation of GNPs in the epoxy matrix has improved the extent of Cf-Ep adhesion as can be observed in Cf-Ep/1GNPs hybrid composite (Figure 2(b)). It is very interesting to note that the 2-d GNPs has considerably improved the Cf/Ep interfacial adhesion to pronounced extent in hybrid composite and that has been revealed from the sound adhered epoxy matrix on the fiber surface as presented in Figure 2(b).

\subsection{Density of Mono and Hybrid Composites}

Density is an important parameter used to estimate the porosity of resultant mono or hybrid composites and most of the structural applications consider density as a principal characteristic. The effects of GNPs loading on density of the virgin epoxy and Cf-Ep hybrid composites produced are listed in Table 2. Generally due to the presence of porosity and voids, there is continuously some variation happens between actual and theoretical density values. According to the "rule of mixture" the theoretical density of Epon 828 with $0.5 \mathrm{wt} \%$ of GNPs is $1.547 \mathrm{~g} \cdot \mathrm{cm}^{-3}$. The measured density of the GNPS-Ep mono-composites marginally varied with three-roll mill mixing followed by sonication method used for fabrication. The distribution of GNPs is prejudiced by good wettability of nanoparticles in the epoxy resin.

Table 2 shows the mean ( \pm upper and lower deviation) measured density of 
Table 2. Density and voids of mono and hybrid nanocomposites.

\begin{tabular}{cccc}
\hline \multirow{2}{*}{ Composites } & \multicolumn{3}{c}{ Mechanical Properties } \\
\cline { 2 - 4 } & $\begin{array}{c}\text { Theoretical } \\
\text { Density }\left(\mathrm{g} / \mathrm{cm}^{3}\right)\end{array}$ & $\begin{array}{c}\text { Measured Density } \\
\left(\mathrm{g} / \mathrm{cm}^{3}\right)\end{array}$ & $\begin{array}{c}\text { Voids } \\
(\%)\end{array}$ \\
\hline $\begin{array}{c}\text { Epon 828 } \\
\text { (Ep) }\end{array}$ & 1.16 & $1.148 \pm 0.02$ & 1.03 \\
GNPs filled epoxy (0.5 GNPs-Ep) & 1.159 & $1.141 \pm 0.03$ & 1.55 \\
GNPs filled epoxy (1.0 GNPs-Ep) & 1.157 & $1.135 \pm 0.02$ & 1.90 \\
GNPs filled epoxy (1.5 GNPs-Ep) & 1.156 & $1.123 \pm 0.05$ & 2.86 \\
GNPs filled epoxy (2.0 GNPs-Ep) & 1.155 & $1.118 \pm 0.04$ & 3.20 \\
Carbon fabric-Epon 828 (Cf-Ep) & 1.507 & $1.477 \pm 0.02$ & 2.0 \\
Cf-Epon 828 with GNPs (Cf-Ep/1.0GNPs) & 1.504 & $1.464 \pm 0.05$ & 2.7 \\
\hline
\end{tabular}

mono and hybrid nanocomposites. The measured density of mono-composites decreases almost near linearly with increasing GNPs loading. According to the linear fitting, the trend for measured density of mono-composites is $\mathrm{y}=0.0013 \mathrm{x}$ +1.16 and $\mathrm{R}^{2}=0.9657$. It is clear from Table 2 that there is considerable decrease in voids for $0.5 \mathrm{wt} \%$ and $1 \mathrm{wt} \%$ GNPs filled epoxy composites. However, the voids are increased for $1.5 \mathrm{wt} \%$ and $2 \mathrm{wt} \%$ filled epoxy composites because of agglomeration. The decrease in voids for lower filler loading could be due to lower volume, and good as well as better interfacial bonding between the GNPs and epoxy in the final composites. These results indicate combination of three-roll mill and sonication mixing helps to reduce the porosity in especially lower nanofiller $(<1 \mathrm{wt} \%)$ filled epoxy mono-composites.

The fiber volume fraction of Cf-Ep and hybrid nanocomposite slabs was calculated following ASTM D 3171. The mean values of fiber volume fraction of Cf-Ep and hybrid nanocomposite slabs were $56.4 \%$ and $51.8 \%$ individually. Addition of GNPs increased the viscosity of Epon 828 and entrapped air which circumscribed the congestion of resin and that may be the reason for increased volume fraction of voids in hybrid nanocomposites (Table 2; Cf-Ep and Cf-Ep/1GNPs).

\subsection{Hardness of Mono and Hybrid Composites}

The Shore hardness tests (Shore-D) were performed on the fabricated mono and hybrid nanocomposites as per ASTM standard. The indentation of the coupon at ten different locations was noticed and the averages of the measured values were taken.

Figure 3 shows the Shore-D hardness of the nanocomposite coupons which expanded by a generally excellent edge for mono-composite system. The glassy surface finish was seen for mono-nanocomposites. The hardness value of 71 (Shore-D) for the pristine Ep and the coupons of mono-nanocomposites Ep with GNPs expanded up to 80 for the $2 \mathrm{wt} \%$ (2GNPs-Ep) as it is improved by $12.7 \%$ and followed an improvement of $9.9 \%$ with 1.5GNPs-Ep nanocomposites (Table 2 ). The explanation behind this pattern might be credited to the conceivable 


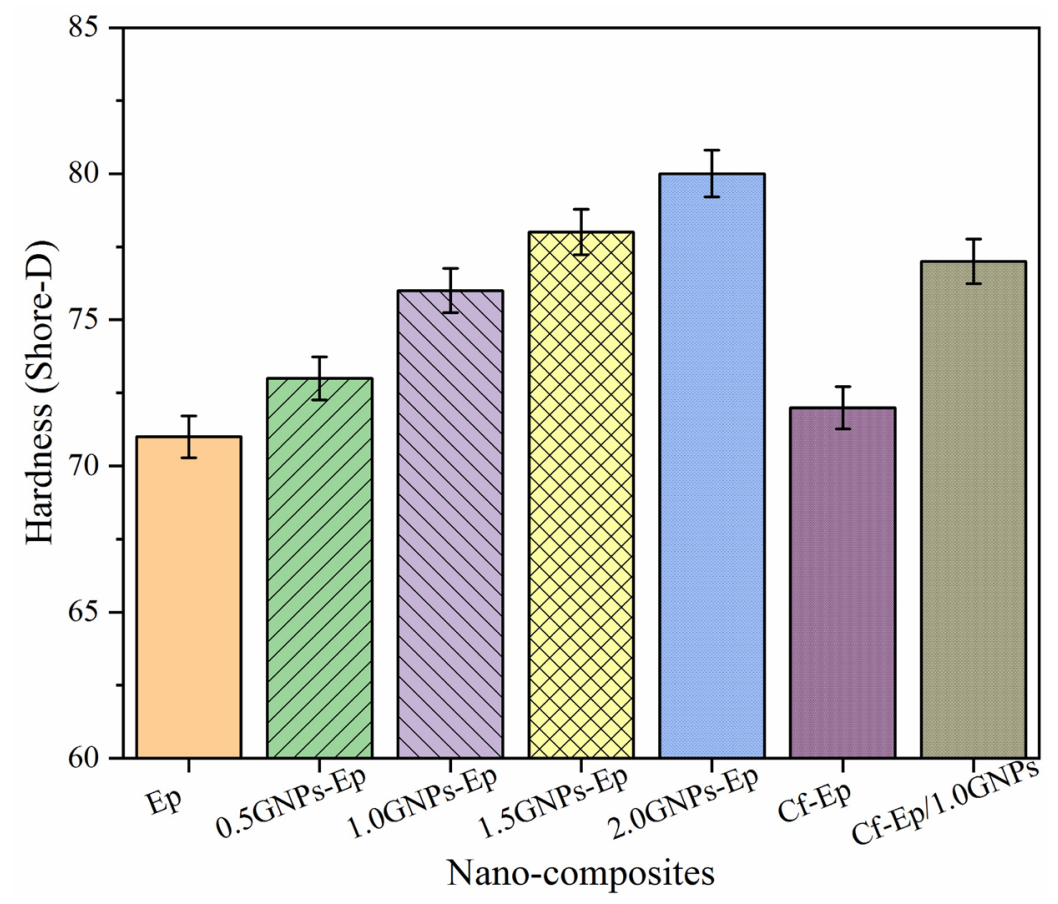

Figure 3. Hardness of mono and hybrid nanocomposites.

hydrogen bonding between the hydroxyl and carbonyl groups of graphene with that of epoxy resin [49]. Diminishing hardness estimations of 72 and 77 were seen for Cf-Ep and Cf-Ep/1GNPs hybrid nanocomposites. This expansion in hardness for mono-nanocomposites is because of density of cross linking favors improvement in hardness. However, for unfilled Cf-Ep composite doesn't give any change in light of the fact that the outside of the Cf-Ep is filled distinctly by Ep matrix material. Measured hardness information sign that the epoxy matrix turns out to be increasingly adaptable affected by the GNPs utilized in the examination. From the obtained hardness information for hybrid nanocomposite, it tends to be presumed that the hardness is diminished with the incorporation of GNPs. As a rule, the addition of GNPs with various loadings increases the hardness contrasted with pristine Ep. Comparable discoveries likewise got by Molazemhosseini et al. [50], which showed that the expansion of little weight divisions of silica nanoparticles can mend the hardness of PEEK-hybrid composites strengthened with short carbon-fibers with increment in hardness as the loading of nanoparticles escalates. As the weight fraction of nanoparticle upsurges, filler particles plug in the hole between the fiber and matrix and structure an increasingly thick structure and hence the hardness raises [51].

\subsection{Tensile Properties of Mono and Hybrid Composites}

The mechanical performance of the GNPs filled Ep and Cf-Ep with $1.0 \mathrm{wt} \%$ GNPs loading are important for structural applications. Figure 4 shows the tensile stress/strain curves of these nanocomposites. The results revealed that the GNPs loading had a profound effect on both tensile strength and modulus 
of the composites. It is found (see Table 3) that an increase in GNPs loading in Ep up to $1 \mathrm{wt} \%$ leads to an increase in both tensile strength as well as modulus of elasticity of the epoxy nanocomposites. A further increase in GNPs loading up to $2 \mathrm{wt} \%$, causes decrease in tensile strength and modulus of elasticity of mono-nanocomposites, which is consistent with the observation in the tensile properties of other epoxy/graphene composites [52]. The reason for decrease in strength and fracture strain in $1.5 \mathrm{wt} \%$ and $2 \mathrm{wt} \%$ GNPs-Ep nanocomposites could be due to the microscopic separation and the stiffness of GNPs. The maximal tensile strength $(72.01 \mathrm{MPa})$ and tensile modulus $(2.73 \mathrm{GPa})$ are shown by the epoxy composite with 1 wt\% GNPs loading. From Figure 4, it can be seen that the linear elastic region is revealed at low strains of $14 \%-18 \%$ for GNPs-Ep nanocomposites. Further, it can also be seen that the elastic region of pristine Ep and 0.5 GNPs-Ep is greater than that of other GNPs filled Ep nanocomposites. This indicated that incorporation of GNPs into Ep matrix resulted in strong interactions between GNPs and Ep matrix material, which restricted the motion of the Ep matrix. However, for CF-Ep with GNPs hybrid composites, the linear elastic region is revealed at high strains of $80 \%-90 \%$. From the results it can be concluded that there exist an optimum filler loading of $1 \mathrm{wt} \%$ in Ep matrix material.

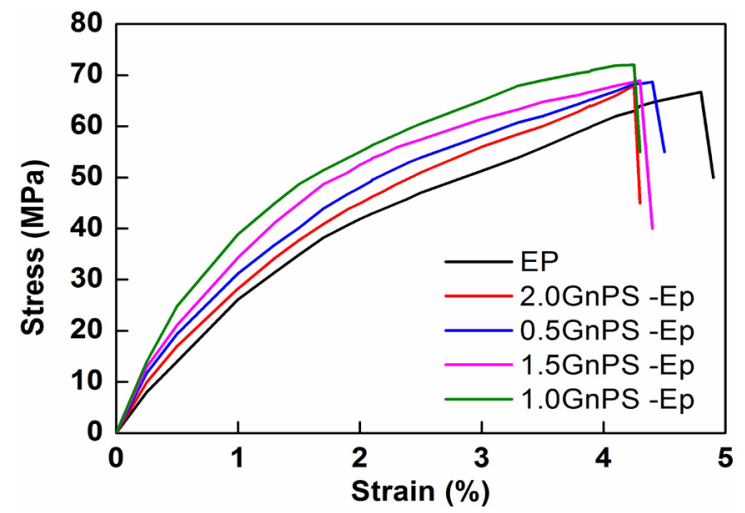

Figure 4. Typical stress/strain curves under tensile mode for mono-nanocomposites.

Table 3. Mechanical properties of mono and hybrid nancomposites.

\begin{tabular}{cccc}
\hline & \multicolumn{3}{c}{ Mechanical Properties } \\
\cline { 2 - 4 } Composites & $\begin{array}{c}\text { Tensile Strength } \\
(\mathrm{MPa})\end{array}$ & $\begin{array}{c}\text { Tensile Modulus } \\
(\mathrm{GPa})\end{array}$ & Fracture Strain (\%) \\
\hline Ep & $66.71 \pm 3.5$ & $2.35 \pm 0.5$ & $4.80 \pm 0.1$ \\
0.5 GNPs-Ep & $68.71 \pm 2.3$ & $2.49 \pm 0.9$ & $4.40 \pm 0.2$ \\
1.0 GNPs-Ep & $72.01 \pm 2.9$ & $2.73 \pm 0.8$ & $4.25 \pm 0.1$ \\
1.5 GNPs-Ep & $68.95 \pm 2.6$ & $2.48 \pm 1.2$ & $4.32 \pm 0.3$ \\
2.0 GNPs-Ep & $67.98 \pm 3.1$ & $2.47 \pm 1.4$ & $4.25 \pm 0.4$ \\
Cf-Ep & $724.40 \pm 8.5$ & $64.82 \pm 1.5$ & $3.13 \pm 0.1$ \\
CF-Ep/1.0GNPs & $754.56 \pm 6.5$ & $70.65 \pm 0.5$ & $3.21 \pm 0.2$ \\
\hline
\end{tabular}


The experimental results of tensile tests of pristine Ep and its GNPs filled Ep nanocomposites with different GNPs loading, comprising tensile strength, tensile modulus, and fracture strains are summarized in Table 3. It is evident that both the tensile strength and modulus of elasticity for GNPs filled Ep nanocomposites accomplished a certain increase when compared to pristine Ep, whereas there are some striking differences. The tensile strength and modulus of elasticity for GNPs filled Ep nanocomposites reached the maximum value simultaneously at the GNPs loading of $1 \mathrm{wt} \%$ with a slight increase of $8 \%$ and $12 \%$, respectively, and both properties of other GNPs loaded Ep coupons decreased with further increasing GNPs loading. However, the tensile strength and modulus of elasticity for CF-Ep/GNPs hybrid nanocomposites reached the maximum value simultaneously at the GNPs loading of $1 \mathrm{wt} \%$ with a trivial increase of $4 \%$ and $9 \%$, respectively when compared to unfilled CF-Ep composites. The addition of GNPs slightly increased the stiffness of epoxy matrix material. The reinforcement effect was from the transfer of the mechanical properties of the GNPs, which was also ascribed to the enriched interfacial adhesion [53]. The higher tensile properties achieved for mono and hybrid nanocomposites can be attributed to the following explanation: 1) long-chain graphene has better compatibility with the Ep matrix; 2) the toughen modifier offered a good compatibility with epon 828 matrix and GNPs/carbon fiber reinforcement. Further, larger layer spacing is more conducive to the solvent on its exfoliating, which permits the GNPs to be uniformly dispersed in the Ep matrix. Such exceptional dispersion and good compatibility are not only beneficial for improving the load transfer between Ep/GNPs/Cfs, nevertheless also augmenting the energy dissipation of the nanocomposites during fracture process. Furthermore, high loading of GNPs (1.5 wt\% and $2 \mathrm{wt} \%$ ) in Ep could lead to typical agglomerate of graphene layers cause a stress concentration during the fracture testing. this phenomenon was accountable for damaging stress transfer from the Ep to the graphene layers, causing worsening of the mechanical properties. Similar degradation in the tensile properties of graphene in epoxy composites was observed in the literature [30] [54].

\subsection{Flexural Properties of Mono and Hybrid Composites}

Table 4 and Figure 5(a), Figure 5(b) displays the effect of GNPs loading on the flexural strength, modulus, and fracture strain of mono and hybrid nanocomposites. When the loading of GNPs is up to $1 \mathrm{wt} \%$, the strengthening effect is more significant and consistent with the tensile properties. Further loading of GNPs (>1 wt\%) into the epoxy matrix, the flexural strength can be made to decrease from 105.01 MPa of 1GNPs-Ep nanocomposite to $94.45 \mathrm{MPa}$ and $93.56 \mathrm{MPa}$ of the $1.5 \mathrm{wt} \%$ and $2 \mathrm{wt} \%$ loading of GNPs-Ep nanocomposites (approximately, a decrease of $10 \%$ - 11\%). Similarly, the flexural modulus decreases from $2.79 \mathrm{GPa}$ of 1 GNPs-Ep nanocomposite to $2.63 \mathrm{GPa}$ and $2.62 \mathrm{GPa}$ of the $1.5 \mathrm{wt} \%$ and 2 wt $\%$ loading of GNPs-Ep nanocomposites, a decrease of $6 \%$. Furthermore, in- 
crease of GNPs $>1 \mathrm{wt} \%$, may cause the decrease in the flexural strength and modulus of the Ep nanocomposites, which may be due to the presence of GNPs agglomerates. Nonetheless the flexural strength and modulus is still better than that of the pristine Ep matrix. It can be clearly seen from Table 4 that the flexural strength/modulus enhancement effect is superior when lower loadings $(0.5$ and $1 \mathrm{wt} \%$ ) of GNPs are added to the Epon 828 matrix. Moreover, as the loading of GNPs is less ( $\leq 1 \mathrm{wt} \%)$, the reinforcement effect has been remarkable. The flexural strength and modulus of the $1 \mathrm{wt} \%$ loading GNPs-Ep nanocomposite is 105.01 $\mathrm{MPa}$ and 2.75 GPa, respectively. Therefore, the flexural strength and modulus on flexural property increase by $14 \%$ and $10 \%$, respectively, compared with that of pristine Epon 828 matrix. The improvement of the flexural strength and flexural modulus is attributed to the better dispersion and exfoliation of GNPs in Epon 828 matrix, consistent with the exploration of tensile properties, resulting in higher stress transfer efficiency and better strengthening effect.

\subsection{Impact Strength of Mono and Hybrid Composites}

The impact strength of mono and hybrid nanocomposites is as shown in Figure 6. Well dispersed GNPs considerably increase impact strength of Ep matrix up
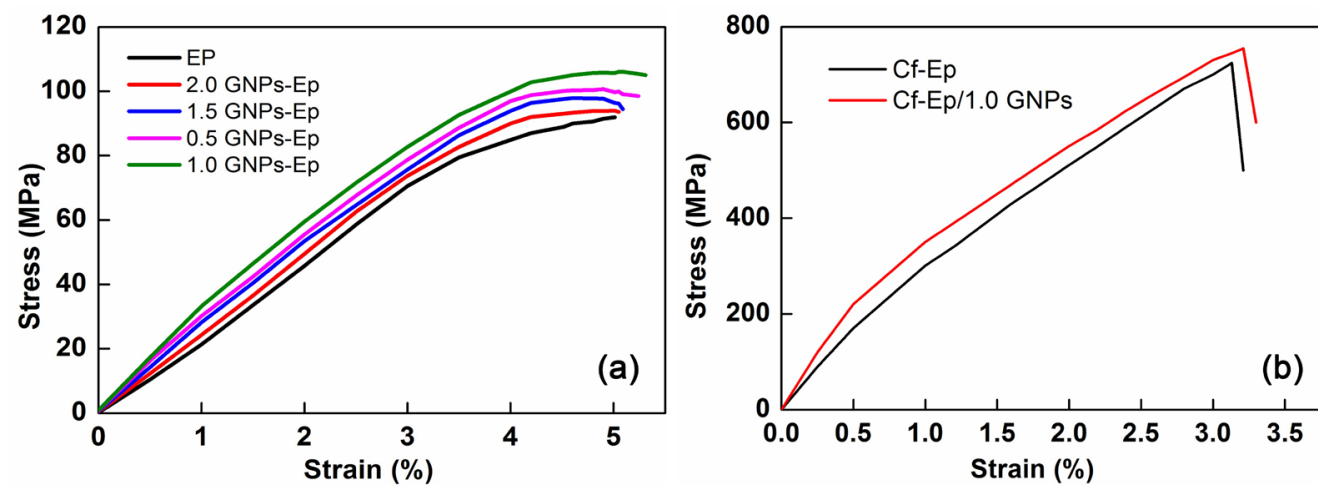

Figure 5. Typical stress/strain curves under flexure mode for: (a) Mono-nanocomposites, (b) hybrid nanocomposites.

Table 4. Flexural properties of mono and hybrid nanocomposites.

\begin{tabular}{cccc}
\hline & \multicolumn{3}{c}{ Mechanical Properties } \\
\cline { 2 - 4 } Composites & $\begin{array}{c}\text { Flexural Strength } \\
(\mathrm{MPa})\end{array}$ & $\begin{array}{c}\text { Flexural Modulus } \\
(\mathrm{GPa})\end{array}$ & Fracture Strain (\%) \\
\hline Ep & 91.89 & 2.54 & 5.01 \\
0.5 GNPs-Ep & 98.56 & 2.75 & 5.24 \\
1.0 GNPs-Ep & 105.01 & 2.79 & 5.31 \\
1.5 GNPs-Ep & 94.45 & 2.63 & 5.09 \\
2.0 GNPs-Ep & 93.56 & 2.62 & 5.05 \\
Cf-Ep & 724.40 & 64.82 & 3.13 \\
CF-Ep/1.0GNPs & 754.56 & 70.65 & 3.21 \\
\hline
\end{tabular}


to $1.5 \mathrm{wt} \%$. Ep with $1.5 \mathrm{wt} \%$ GNPs shows about $61 \%$ higher impact strength in comparison with pristine matrix material. The increase in impact strength may be due to micro-plastic deformation forming round the GNPs. Similar trend with increase in impact strength, due to improved interfacial bonding between the functionalized graphene nanoplatelets and the epoxy matrix was found in the reference [35]. Pristine Ep with higher loading of GNPs (>1.5 wt\%) showed the decrease of impact strength in comparison with other mono-composites. Likewise, Liu et al. and Wei et al. [54] [55] probed the interphase of epoxy/graphene oxide and reported upsurge in the modulus and toughness. Reason of adverse impact properties is agglomeration of nanoparticles in pristine Ep matrix. Izod impact strength of unfilled Cf-Ep and 1 GNPs filled CF-Ep hybrid nanocomposites is compared with mono-nanocomposites and are shown in Figure 6. Results clearly show incorporation of carbon fabric and GNPs in Ep have got favourable influence on impact strength of nanocomposites on the base of the pristine Ep matrix.

\section{Conclusions}

- Graphene filled epoxy and their hybrid nanocomposites are stimulating new materials which are finding place in electrical, electronics, automotive, and construction industries. The remarkably higher mechanical properties of epoxy with graphene nano-reinforcement make them flawless material to strengthen the composites. Microstructure and physico-mechanical properties evaluations were accomplished in Epon 828 epoxy nanocomposites modified with GNPs and carbon fibers.

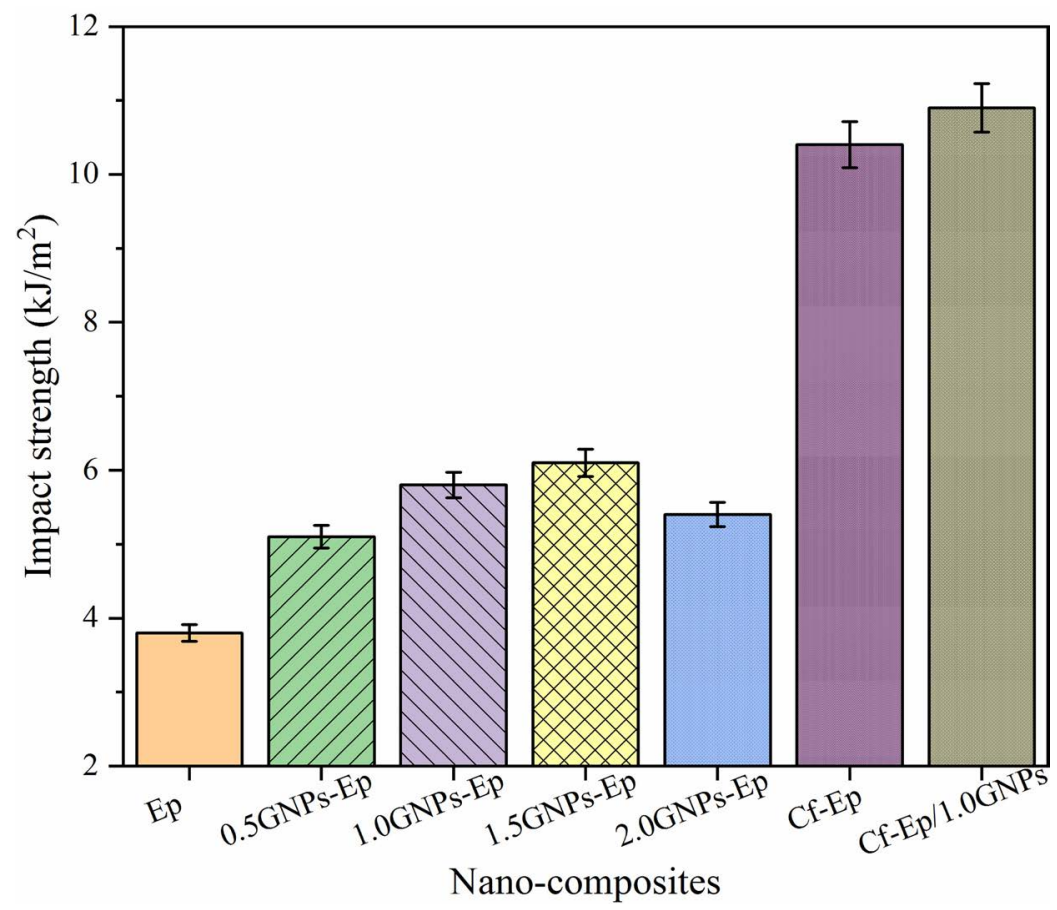

Figure 6. Impact strength of mono and hybrid nanocomposites. 
- Fractographs form scanning electron microscopic remarks a transition from total brittle Ep (0 wt $\%$ GNPs) to moderately ductile (0.5 wt $\%$ to $2 \mathrm{wt} \%)$ fracture.

- The use of GNPs in Ep and Cf-Ep fetches improvement in the mechanical properties of nanocomposites. However, an optimal loading of $1 \mathrm{wt} \%$ GNPs has been observed in mono and hybrid nanocomposites.

- The tensile strength and modulus increased by adding GNPs into Ep, and GNPs up to $1 \mathrm{wt} \%$ loading as compared to Cf-Ep composites. However, further addition of GNPs (>1 wt\%) slightly reduced the strength and modulus values as compared to other nanocomposites.

- A increment in flexural strength (105.01 MPa) and bending modulus (2.79 $\mathrm{GPa})$ for the $1 \mathrm{wt} \%$ GNPs-Ep nanocomposite and flexural strength (754.56 $\mathrm{MPa}$ ) and bending modulus (70.65 GPa) for the $1 \mathrm{wt} \%$ GNPs in CF-Ep hybrid nanocomposite were found in comparison with pristine Ep matrix (91.98 $\mathrm{MPa}$ and 2.54 GPa), respectively.

- Well-dispersed nanoparticles of GNPs up to the loading of about $1.5 \mathrm{wt} \%$ increase Izod impact absorbed energy of Ep matrix. Under hybrid nanocomposites, both carbon fibers and GNPs loading of $1 \mathrm{wt} \%$ also enhanced the impact absorbed energy of Ep matrix. Ample increment was found for the Izod impact absorbed energy from the pristine epoxy $\left(3.8 \mathrm{~J} / \mathrm{m}^{2}\right)$ to $1.5 \mathrm{wt} \% \mathrm{GNPs}$ filled Ep $\left(6.1 \mathrm{~J} / \mathrm{m}^{2}\right)$ and 1.0 GNPs in CF-Ep hybrid nanocomposites (10.9 $\left.\mathrm{J} / \mathrm{m}^{2}\right)$.

\section{Funding}

This research received no specific grant from any funding agency.

\section{Conflicts of Interest}

The authors declare no conflicts of interest regarding the publication of this paper.

\section{References}

[1] Üstün, T., Ulus, H., Karabulut, S.E., Eskizeybek, V., Şahin, Ö.S., Avc1, A. and Demir, O. (2016) Evaluating the Effectiveness of Nanofillers in Filament Wound Carbon/Epoxy Multiscale Composite Pipes. Composites Part B: Engineering, 96, 1-6. https://doi.org/10.1016/j.compositesb.2016.04.031

[2] Suresha, B., Chandramohan, G. and Renukappa, N.M. (2007) Mechanical and Tribological Properties of Glass-Epoxy Composites with and without Graphite Particulate Filler. Journal of Applied Polymer Science, 103, 2472-2480. https://doi.org/10.1002/app.25413

[3] Suresha, B. and Kumar, K.N.S. (2009) Investigations on Mechanical and Two-Body Abrasive Wear Behaviour of Glass/Carbon Fabric Reinforced Vinyl Ester Composites. Materials \& Design, 30, 2056-2060. https://doi.org/10.1016/j.matdes.2008.08.038

[4] Rafique, I., Kausar, A. and Muhammad, B. (2016) Epoxy Resin Composite Reinforced with Carbon Fiber and Inorganic Filler: Overview on Preparation and Prop- 
erties. Polymer-Plastics Technology and Engineering, 55, 1653-1672. https://doi.org/10.1080/03602559.2016.1163597

[5] Suresha, B., Ramesh, B.N., Subbaya, K.M. and Chandramohan, G. (2010) Mechanical and Three-Body Abrasive Wear Behavior of Carbon-Epoxy Composite with and without Graphite Filler. Journal of Composite Materials, 44, 2509-2519. https://doi.org/10.1177/0021998310369589

[6] Suresha, B., Chandramohan, G., Shivakumar, K.N. and Ismail, M. (2008) Mechanical and Three-Body Abrasive Wear Behaviour of Three-Dimensional Glass Fabric Reinforced Vinyl Ester Composite. Materials Science and Engineering. A, 480, 573-579. https://doi.org/10.1016/j.msea.2007.07.011

[7] Khashaba, U.A., Aljinaidi, A.A. and Hamed, M.A. (2014) Nanofillers Modification of Epocast 50-A1/946 Epoxy for Bonded Joints. Chinese Journal of Aeronautics, 27, 1288-1300. https://doi.org/10.1016/j.cja.2014.08.007

[8] Han, W., Tang, Y. and Ye, L. (2017) Carbon Fibre-Reinforced Polymer Laminates with Nanofiller-Enhanced Multifunctionality. In: The Structural Integrity of Carbon Fiber Composites, Springer, Cham, 171-197. https://doi.org/10.1007/978-3-319-46120-5 8

[9] Bhattacharya, M. (2016) Polymer Nanocomposites-A Comparison between Carbon Nanotubes, Graphene, and Clay as Nanofillers. Materials, 9, 262. https://doi.org/10.3390/ma9040262

[10] Adak, N.C., Chhetri, S., Kim, N.H., Murmu, N.C., Samanta, P. and Kuila, T. (2018) Static and Dynamic Mechanical Properties of Graphene Oxide-Incorporated Woven Carbon Fiber/Epoxy Composite. Journal of Materials Engineering and Performance, 27, 1138-1147. https://doi.org/10.1007/s11665-018-3201-5

[11] Park, S.J., Jin, F.L. and Lee, J.R. (2004) Thermal and Mechanical Properties of Tetrafunctional Epoxy Resin Toughened with Epoxidized Soybean Oil. Materials Science and Engineering. A, 374, 109-114. https://doi.org/10.1016/j.msea.2004.01.002

[12] May, C. (2018) Epoxy Resins: Chemistry and Technology. Routledge, Abingdon-on-Thames. https://doi.org/10.1201/9780203756713

[13] Kurahatti, R.V., Surendranathan, A.O., Srivastava, S., Singh, N., Kumar, A.R. and Suresha, B. (2011) Role of Zirconia Filler on Friction and Dry Sliding Wear Behaviour of Bismaleimide Nanocomposites. Materials \& Design, 32, 2644-2649. http://idr.nitk.ac.in/jspui/handle/123456789/12833 https://doi.org/10.1016/j.matdes.2011.01.030

[14] Manjunath, M., Renukappa, N.M. and Suresha, B. (2016) Influence of Micro and Nanofillers on Mechanical Properties of Pultruded Unidirectional Glass Fiber Reinforced Epoxy Composite Systems. Journal of Composite Materials, 50, 1109-1121. https://doi.org/10.1177/0021998315588623

[15] Udaya Kumar, P.A., Suresha, B., Rajini, N. and Satyanarayana, K.G. (2018) Effect of Treated Coir Fiber/Coconut Shell Powder and Aramid Fiber on Mechanical Properties of Vinyl Ester. Polymer Composites, 39, 4542-4550. https://doi.org/10.1002/pc.24561

[16] Suresha, B., Devarajaiah, R.M., Pasang, T. and Ranganathaiah, C. (2013) Investigation of Organo-Modified Montmorillonite Loading Effect on the Abrasion Resistance of Hybrid Composites. Materials \& Design, 47, 750-758. https://doi.org/10.1016/j.matdes.2012.12.056

[17] Ahmad, M.A., Güven, G.G. and Sarıkavaklı, N. (2019) Some Features of Doping of Nano-Graphite in Natural Coir Fibre Epoxy Composites. Avrupa Bilim ve Teknoloji 
Dergisi, 15, 491-498. https://doi.org/10.31590/ejosat.540021

[18] Yang, S.Y., Lin, W.N., Huang, Y.L., Tien, H.W., Wang, J.Y., Ma, C.C.M., Li, S.M. and Wang, Y.S. (2011) Synergetic Effects of Graphene Platelets and Carbon Nanotubes on the Mechanical and Thermal Properties of Epoxy Composites. Carbon, 49, 793-803. https://doi.org/10.1016/j.carbon.2010.10.014

[19] Pathak, A.K., Borah, M., Gupta, A., Yokozeki, T. and Dhakate, S.R. (2016) Improved Mechanical Properties of Carbon Fiber/Graphene Oxide-Epoxy Hybrid Composites. Composites Science and Technology, 135, 28-38. https://doi.org/10.1016/j.compscitech.2016.09.007

[20] Yao, H., Sui, X., Zhao, Z., Xu, Z., Chen, L., Deng, H., Liu, Y. and Qian, X. (2015) Optimization of Interfacial Microstructure and Mechanical Properties of Carbon Fiber/Epoxy Composites via Carbon Nanotube Sizing. Applied Surface Science, 347, 583-590. https://doi.org/10.1016/j.apsusc.2015.04.146

[21] Njuguna, J., Pielichowski, K. and Desai, S. (2008) Nanofiller Reinforced Polymer Nanocomposites. Polymers for Advanced Technologies, 19, 947-959. https://doi.org/10.1002/pat.1074

[22] Imran, K.A. and Shivakumar, K.N. (2018) Enhancement of Electrical Conductivity of Epoxy Using Graphene and Determination of Their Thermo-Mechanical Properties. Journal of Reinforced Plastics and Composites, 37, 118-133. https://doi.org/10.1177/0731684417736143

[23] Du, J. and Cheng, H.M. (2012) The Fabrication, Properties, and Uses of Graphene/Polymer Composites. Macromolecular Chemistry and Physics, 213, 1060-1077. https://doi.org/10.1002/macp.201200029

[24] Lee, C., Wei, X. and Kysar, J.W. (2008) Measurement of the Elastic Properties and Intrinsic Strength of Monolayer Graphene. Science, 321, 385-388. https://doi.org/10.1126/science.1157996

[25] King, J.A., Klimek, D.R. and Miskioglu, I. (2013) Mechanical Properties of Graphene Nanoplatelet/Epoxy Composites. Journal of Applied Polymer Science, 128, 4217-4223. https://doi.org/10.1002/app.38645

[26] Raza, M.A., Westwooda, A.V.K. and Stirling, C. (2012) Effect of Processing Technique on the Transport and Mechanical Properties of Graphite Nanoplatelet/Rubbery Epoxy Composites for Thermal Interface Applications. Materials Chemistry and Physics, 132, 63-73. https://doi.org/10.1016/j.matchemphys.2011.10.052

[27] Drzal, L.T. and Fukushima, H. (2017) Exfoliated Graphite Nanoplatelets (xGnP): A Carbon Nanotube Alternative. NSTI-Nanotech, 1, 170-173. http://www.nsti.org

[28] Monti, M., Rallini, M. and Puglia, D. (2013) Morphology and Electrical Properties of Graphene-Epoxy Nanocomposites Obtained by Different Solvent Assisted Processing Methods. Composites Part A, 46, 166-172. https://doi.org/10.1016/j.compositesa.2012.11.005

[29] Wajid, A.S., Ahmed, H.S.T. and Das, S. (2013) High-Performance Pristine Graphene/Epoxy Composites with Enhanced Mechanical and Electrical Properties. Macromolecular Materials and Engineering, 298, 339-347. https://doi.org/10.1002/mame.201200043

[30] Tang, L.C., Wan, Y.J. and Yan, D. (2013) The Effect of Graphene Dispersion on the Mechanical Properties of Graphene/Epoxy Composites. Carbon, 60, 16-27. https://doi.org/10.1016/j.carbon.2013.03.050

[31] Wan, Y.J., Gong, L.X., Tang, L.C., Wu, L.B. and Jiang, J.X. (2014) Mechanical Properties of Epoxy Composites Filled with Silane-Functionalized Graphene Oxide. Composites Part A: Applied Science and Manufacturing, 64, 79-89. 
https://doi.org/10.1016/j.compositesa.2014.04.023

[32] Wan, Y.J., Tang, L.C., Gong, L.X., Yan, D., Li, Y.B., Wu, L.B., Jiang, J.X. and Lai, G.Q. (2014) Grafting of Epoxy Chains onto Graphene Oxide for Epoxy Composites with Improved Mechanical and Thermal Properties. Carbon, 69, 467-480.

https://doi.org/10.1016/j.carbon.2013.12.050

[33] Ghaleb, Z.A., Mariatti, M. and Ariff, Z.M. (2018) Preparation and Properties of Amine Functionalized Graphene Filled Epoxy Thin Film Nano Composites for Electrically Conductive Adhesive. Journal of Materials Science: Materials in Electronics, 29, 3160-3169. http://ir.unimas.my/id/eprint/19937 https://doi.org/10.1007/s10854-017-8249-8

[34] Wang, X., Jin, J. and Song, M. (2013b) An Investigation of the Mechanism of Graphene Toughening Epoxy. Carbon, 65, 324-333.

https://doi.org/10.1016/j.carbon.2013.08.032

[35] Seong, M. and Kim, D.S. (2015) Effects of Facile Amine Functionalization on the Physical Properties of Epoxy/Graphene Nanoplatelets Nanocomposites. Journal of Applied Polymer Science, 132, 42269-42275. https://doi.org/10.1002/app.42269

[36] Yavari, F., Rafiee, M.A., Rafiee, J., Yu, Z.Z. and Koratkar, N. (2010) Dramatic Increase in Fatigue Life in Hierarchical Graphene Composites. ACS Applied Materials \& Interfaces, 2, 2738-2743. https://doi.org/10.1021/am100728r

[37] Bozkurt, E., Kaya, E. and Tanoğlu, M. (2007) Mechanical and Thermal Behavior of Non-Crimp Glass Fiber Reinforced Layered Clay/Epoxy Nanocomposites. Composites Science and Technology, 67, 3394-3403. https://doi.org/10.1016/j.compscitech.2007.03.021

[38] He, H. and Li, K. (2012) Silane Coupling Agent Modification on Interlaminar Shear Strength of Carbon Fiber/Epoxy/Nano $\mathrm{CaCo}_{3}$ Composites. Polymer Composites, 33, 1755-1758. https://doi.org/10.1002/pc.22311

[39] Davis, D.C., Wilkerson, J.W., Zhu, J. and Hadjiev, V.G. (2011) A Strategy for Improving Mechanical Properties of a Fiber Reinforced Epoxy Composite Using Functionalized Carbon Nanotubes. Composites Science and Technology, 71, 1089-1097. https://doi.org/10.1016/j.compscitech.2011.03.014

[40] Ashori, A., Rahmani, H. and Bahrami, R. (2015) Preparation and Characterization of Functionalized Graphene Oxide/Carbon Fiber/Epoxy Nanocomposites. Polymer Testing, 48, 82-88. https://doi.org/10.1016/j.polymertesting.2015.09.010

[41] Wang, F., Drzal, L.T., Qin, Y. and Huang, Z. (2016) Size Effect of Graphene Nanoplatelets on the Morphology and Mechanical Behavior of Glass Fiber/Epoxy Composites. Journal of Materials Science, 51, 3337-3348.

https://doi.org/10.1007/s10853-015-9649-X

[42] Qin, W., Vautard, F., Drzal, L.T. and Yu, J. (2015) Mechanical and Electrical Properties of Carbon Fiber Composites with Incorporation of Graphene Nanoplatelets at the Fiber-Matrix Interphase. Composites Part B: Engineering, 69, 335-341. https://doi.org/10.1016/j.compositesb.2014.10.014

[43] Zhao, Z., Teng, K., Li, N., Li, X., Xu, Z., Chen, L., Niu, J., Fu, H., Zhao, L. and Liu, Y. (2017) Mechanical, Thermal and Interfacial Performances of Carbon Fiber Reinforced Composites Flavored by Carbon Nanotube in Matrix/Interface. Composite Structures, 159, 761-772. https://doi.org/10.1016/j.compstruct.2016.10.022

[44] Zhang, X., Fan, X., Yan, C., Li, H., Zhu, Y., Li, X. and Yu, L., (2012) Interfacial Microstructure and Properties of Carbon Fiber Composites Modified with Graphene Oxide. ACS Applied Materials \& Interfaces, 4, 1543-1552.

https://doi.org/10.1021/am201757v 
[45] Keyte, J., Pancholi, K. and Njuguna, J. (2019) Recent Developments in Graphene Oxide/Epoxy Carbon Fiber-Reinforced Composites. Frontiers in Materials, 6, Article No. 224. https://doi.org/10.3389/fmats.2019.00224

[46] Gao, B., Zhang, R., He, M., Sun, L., Wang, C., Liu, L., Zhao, L., Cui, H. and Cao, A. (2016) Effect of a Multiscale Reinforcement by Carbon Fiber Surface Treatment with Graphene Oxide/Carbon Nanotubes on the Mechanical Properties of Reinforced Carbon/Carbon Composites. Composites Part A: Applied Science and Manufacturing, 90, 433-440. https://doi.org/10.1016/j.compositesa.2016.08.012

[47] Imran, K.A. and Shivakumar, K.N. (2019) Graphene-Modified Carbon/Epoxy Nanocomposites: Electrical, Thermal and Mechanical Properties. Journal of Composite Materials, 53, 93-106. https://doi.org/10.1177/0021998318780468

[48] ASTM, D256-10 (2018) Standard Test Methods for Determining the Izod Pendulum Impact Strength of Plastics. ASTM International, West Conshohocken. https://www.astm.org/Standards/D256

[49] Jayaseelan, J., Palanisamy, P., Vijayakumar, K.R. and Vinita, A.D.M. (2015) Effect of Graphene Filler Content on Mechanical Strength and Hardness for Goat Hair Fibre Reinforced Epoxy Composites. International Journal of Vehicle Structures \& Systems, 7, 165-168.

[50] Molazemhosseini, A., Tourani, H., Khavandi, A. and Eftekhari Yekta, B. (2013) Tribological Performance of PEEK Based Hybrid Composites Reinforced with Short Carbon Fibers and Nano-Silica. Wear, 303, 397-404. https://doi.org/10.1016/j.wear.2013.03.019

[51] Agarwal, G., Patnaik, A. and Sharma, R. (2014) Thermo-Mechanical Properties and Abrasive Wear Behaviour of Silicon Carbide Filled Woven Glass Fiber Composites. Silicon, 6, 155-168. https://doi.org/10.1007/s12633-014-9184-4

[52] Rafiee, M.A., Rafiee, J., Srivastava, I., Wang, Z., Song, H., Yu, Z.Z. and Koratkar, N. (2010) Fracture and Fatigue in Graphene Nanocomposites. Small, 6, 179-183. https://doi.org/10.1002/smll.200901480

[53] Ramanathan, T., Abdala, A.A., Stankovich, S., Dikin, D.A., Herrera-Alonso, M., Piner, R.D., Adamson, D.H., Schniepp, H.C., Chen, X.R.R.S., Ruoff, R.S. and Nguyen, S.T. (2008) Functionalized Graphene Sheets for Polymer Nanocomposites. Nature Nanotechnology, 3, 327-331. https://doi.org/10.1038/nnano.2008.96

[54] Wei, J., Vo, T. and Inam, F. (2015) Epoxy/Graphene Nanocomposites-Processing and Properties: A Review. RSC Advances, 5, 73510-73524. https://doi.org/10.1039/C5RA13897C

[55] Liu, Q., Zhou, X., Fan, X., Zhu, C., Yao, X. and Liu, Z. (2012) Mechanical and Thermal Properties of Epoxy Resin Nanocomposites Reinforced with Graphene Oxide. Polymer-Plastics Technology and Engineering, 51, 251-256.

https://doi.org/10.1080/03602559.2011.625381 